\title{
Contribution of American Pediatricians to Treatment of Diarrheal Dehydration
}

\author{
HAROLD E. HARRISON
}

The Johns Hopkins Hospital, Baltimore, Maryland 21205

American pediatricians have significantly helped the health of children in the world by their studies of water and electrolyte physiology. An important impetus to research in this field was the once-high mortality of infant diarrhea (Table 1). This table, taken from an early edition of Holt's Diseases of Infancy and Childhood (1), indicates that, in the early 1900s, the mortality from infant and early childhood diarrhea in the first two years of life exceeded the combined mortality of all other infectious diseases during the first five years of life.

In 1912, when John Howland came to Johns Hopkins, one of his aims was the application of quantitative chemistry to the understanding of the pathophysiology of disease. One of the diseases that he targeted for study was infant diarrhea. With M. McKim Marriott, he applied the newly developed method of measuring the $\mathrm{CO}_{2}$ content of serum and discovered the severe acidosis of children with diarrheal dehydration; however, i.v. treatment with sodium bicarbonate resulted in only temporary improvement and did not reduce the high mortality rate (2). Oscar Schloss in New York also had found that infants with diarrheal dehydration were severely acidotic and sodium bicarbonate treatment had only a temporary effect (3). He realized it was not a panacea: "Thorough and carefully controlled treatment by sodium bicarbonate usually causes disappearance of the acidosis, but despite this, the infants frequently die from a severe form of malnutrition" (3).

L. Emmett Holt, Sr., at the Babies Hospital in New York, with the aid of two laboratory associates, Courtney and Fales, did the important determination of the ionic composition of stool water of infant diarrhea and found that the concentration of potassium was as great or even greater than that of sodium (Table 2). Previous attention had been given only to sodium and replacement of sodium as the important treatment of diarrheal dehydration. Emmett Holt recognized the possible importance of potassium loss, but had no suggestions as how to proceed in terms of treatment.

Years later, Butler, McKhann, and Gamble of the Children's Hospital of Boston did balance studies of infants with diarrhea (4) and confirmed Holt's finding of a high concentration of potassium in stool water (Table 2). They concluded, however, that there was no use in trying to apply any treatment based upon this observation. They recognized that the potassium loss, which they considered intracellular fluid loss, complicated the problem of diarrheal dehydration, but they did not know how to apply this information to treatment. The authors commented, "The presence of an intracellular fluid loss complicates our conception of the process of dehydration and disturbs our confidence in the therapeutic adequacy of parenteral treatment. Since repair solutions must be placed in the vascular or interstitial compartment, they cannot contain with safety the intracellular materials such as potassium or phosphate, at concentrations above the small values prescribed for them in extracellular fluids" (4). And they realized that "Parenteral therapy has a large, often dramatic effectiveness. It must be admitted, however, that it is not always successful and it may be hoped that recognition of an additional pathologic process in the situation will eventually produce supplementary measures which will provide a more complete control of the severe stage of diarrheal disease" (4).

Darrow, at Yale, provided the solution. The studies of experimental potassium deficiency in his laboratory indicated that intracellular potassium loss was attended with serious physiologic consequences, and that the rate of cell uptake of potassium in states of potassium deficiency was sufficiently rapid so that potassium could be given parenterally, contrary to the advice of Butler, McKhann, and Gamble.

Darrow and Helen Harrison and I had given potassium orally to patients with chronic diarrhea and potassium depletion, with salutary effects. Darrow was now convinced that potassium should be included along with sodium chloride and glucose in the parenteral management of acute diarrhea of infancy.

The opportunity to put this theory to the test came in the summer of 1945 . There was a severe outbreak of infant diarrhea in Baltimore that summer, and Edwards A. Park asked Darrow to come to the Harriet Lane Home to try to improve the treatment of these infants. In August of 1945, Darrow set up a laboratory to do water and electrolyte balances, and all infants with diarrhea admitted to the Harriet Lane Home were given solutions containing potassium, along with the traditional sodium chloride and glucose.

The balance studies indicated that potassium was retained in amounts compatible with repletion of intracellular potassium (5). The treatment was well tolerated and the mortality rate, as shown in Figure 1, was reduced after introduction of potassium therapy. This was the first parenteral use of potassium in the world, and potassium is now regarded as an essential component of all parenteral fluid management. It is particularly valuable for patients on prolonged parenteral maintenance and in such conditions as diabetic ketoacidosis and intestinal obstruction. Sufficient recognition has not been given to Darrow, a member of this Society, a former President, and a Howland Awardee, for this extraordinarily important contribution to the health of, not only children, but adults.

The incidence of infant diarrhea in Baltimore continued to be high. At the Baltimore City Hospital (BCH), I decided to see whether an oral electrolyte solution containing sodium and potassium salts along with a low concentration of glucose might make possible rehydration of infants with diarrhea without parenteral therapy. This would facilitate outpatient treatment of many such infants.

The composition of this original $\mathrm{BCH}$ solution is given in Table 3. The concentrations of sodium and potassium in this solution were based on Darrow's balance studies; the concentration of glucose was based on a theoretical calculation as to the amount of glucose that might reduce the negative protein balance to a minimum. The results with this solution were very satisfactory, fulfilling our hopes of outpatient treatment of many cases of infant diarrhea and reducing the requirement for i.v. therapy (6).

Darrow also studied oral hydration with a solution of somewhat different composition. Within several years, commercial solutions became available, as indicated in Table 3 , but these 
Table 1. Deaths in New York City for five years

\begin{tabular}{lrrrrrrr}
\hline & 1900 & 1901 & 1902 & 1903 & 1904 & Total \\
\hline Measles* & 816 & 449 & 710 & 508 & 895 & 3378 \\
Scarlet fever* & 465 & 1162 & 940 & 734 & 851 & 4152 \\
Pertussis* & 584 & 289 & 606 & 324 & 197 & 2000 \\
Typhoid* & 718 & 727 & 764 & 653 & 661 & 3523 \\
$\begin{array}{l}\text { Diphtheria* } \\
\text { Total deaths from five }\end{array}$ & 1920 & 2068 & 2015 & 2190 & 2084 & 10277 \\
$\quad$ & & & & & & 23330 \\
$\begin{array}{l}\text { diseases } \\
\begin{array}{l}\text { Diarrheal disease, } \\
\quad \text { under two years old }\end{array}\end{array}$ & 5744 & 5796 & 4938 & 4439 & 5646 & 26563 \\
\hline
\end{tabular}

* All ages.

Table 2. Concentrations of sodium and potassium in stool water-infant diarrhea and cholera

\begin{tabular}{lcc}
\hline & $\begin{array}{c}\mathrm{Na} \\
(\mathrm{mEq} / \mathrm{L})\end{array}$ & $\begin{array}{c}\mathrm{K} \\
(\mathrm{mEq} / \mathrm{L})\end{array}$ \\
\hline Holt et al. & 40 & 54 \\
Butler et al. & 67 & 44 \\
Finberg et al. (median) & 61 & 41 \\
Finberg et al. (range) & $5-150$ & $12-117$ \\
Mahalanobis et al. & & \\
$\quad$ Infant diarrhea & 56 & 25 \\
$\quad$ Cholera <5 y & 101 & 27 \\
$\quad$ Cholera-adult & 140 & 13 \\
\hline
\end{tabular}

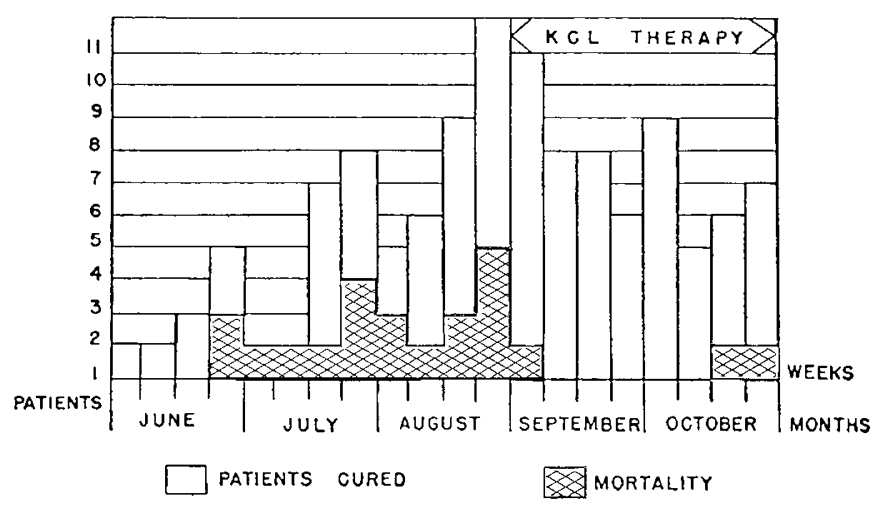

Fig. 1. Patients treated for acute nutritional disturbances.

Table 3. Oral electrolyte solutions in treatment of infant diarrhea

\begin{tabular}{lcccc}
\hline \multicolumn{1}{c}{ Solution } & $\mathrm{Na}$ & $\begin{array}{c}\mathrm{Cl} \\
(\mathrm{mEq} / \mathrm{L})\end{array}$ & $\mathrm{K}$ & $\begin{array}{c}\mathrm{CHO} \\
(\mathrm{gm} / \mathrm{L})\end{array}$ \\
\hline BCH & 64 & 54 & 20 & 33 \\
Lyttren 1 & 50 & 30 & 20 & $53^{*}$ \\
Lyttren 2 & 25 & 30 & 25 & 75 \\
Pedialyte-0 & 30 & 30 & 20 & 50 \\
WHO & 90 & 80 & 20 & 20 \\
Pedialyte-R & 75 & 65 & 20 & 25 \\
Pedialyte-M & 45 & 35 & 20 & 25 \\
$\begin{array}{l}\text { Average Pedialyte-R }+ \\
\quad \text { Pedialyte-M }\end{array}$ & 60 & 50 & 20 & 25 \\
\hline
\end{tabular}

* Dextri-maltose. commercial solutions contained considerably higher concentrations of carbohydrate than the $\mathrm{BCH}$ solution. These high concentrations of organic substances probably were responsible for the osmotic diarrhea and hypernatremic dehydration in some infants given these solutions. This set back the use of oral hydration in this country for many years, because the subsequent solutions that were provided were too low in sodium to be of value in the oral hydration of severe diarrhea.

Meanwhile, another development had occurred outside the United States. An American naval group had been assigned to study the cholera problem during World War II, and this investigation was continued after the war ended. Physiologists in this country investigating sodium absorption by the small intestinal mucosa found a linkage between sodium and glucose transport. The possibility was entertained that a solution of sodium and potassium salts containing only that amount of glucose that would facilitate sodium transport, given orally, could prevent patients with cholera from dying of dehydration and hypovolemia. The solution chosen provided $90 \mathrm{mEq}$ of sodium and 20 $\mathrm{mEq}$ of potassium/L, exactly the same concentration of potassium as in our original $\mathrm{BCH}$ solution. The glucose concentration was somewhat lower, about $2 \%$. The high sodium concentration in this particular solution was selected because stool water concentrations of sodium in cholera are considerably higher than those in infant diarrhea or other etiologies (Table 2).

This oral hydration solution, after some difficulties, was found to be effective by a number of groups working with cholera in various countries in Asia. The success of an oral electrolyte solution in replacing water and electrolyte losses due to cholera prompted the World Health Organization to promote the use of this solution in infant diarrhea. The 1988 report of the United Nations Children's Fund summarizes the value of this program: "The greatest killer of children, with three million victims a year, is still the dehydration caused by diarrheal disease. Yet dehydration can now be prevented by the technique of oral rehydration therapy." This therapy was estimated to be saving more than 600000 lives each year. Dr. Henderson's estimate is even higher than that. Granted, oral rehydration is symptomatic therapy. The need for the prevention of diarrhea is still an important problem that requires technologic advances as well as medical contributions. Symptomatic therapy should still be given credit as effective therapy and, in this case, it has been highly valuable in saving lives.

There has been a reciprocal benefit to us from these studies of oral hydration of diarrhea in Third World countries (7). In this country, suitable commercially marketed solutions for oral replacement of water and electrolyte losses in infant diarrhea are now available, as shown in Table 3 , which gives an example of solutions marketed by one pharmaceutical company; the socalled rehydration solution $(\mathrm{R})$ providing a higher concentration of sodium $(75 \mathrm{mEq} / \mathrm{L})$ and the maintenance solution $(\mathrm{M})$ providing a concentration of sodium of $45 \mathrm{mEq} / \mathrm{L}$. Both solutions contain $20 \mathrm{mEq} / \mathrm{L}$ of potassium. If we average these two solutions, we arrive at a solution containing $60 \mathrm{mEq} / \mathrm{L}$ of sodium, $20 \mathrm{mEq} / \mathrm{L}$ of potassium, and $25 \mathrm{~g}$ glucose $/ \mathrm{L}$. As you can see, this is very close to the composition of the original $\mathrm{BCH}$ solution developed more than 40 years ago.

The contribution of American pediatricians to our knowledge of the water and electrolyte deficits resulting from infant diarrhea has thus helped in the development of relatively simple but effective methods of prevention of dehydration due to diarrhea, which still is a major scourge throughout the world. We can take pride as American pediatricians in this benefit to the health of the world's children.

\section{REFERENCES}

1. Holt LE 1908 The Diseases of Infancy and Childhood. D. Appleton, New York, p 354

2. Howland J, Marriott WM 1916 Acidosis occurring with diarrhea. Am J Dis Child 11:309-325 
3. Schloss OM, Stetson RE 1917 The occurrence of acidosis with severe diarrhea. Am J Dis Child 13:218-230

4. Butler AM, McKhann CF, Gamble JL 1933 Intracellular fluid loss in diarrheal disease. J Pediatr 3:84-92

5. Govan CD, Darrow DC 1946 The use of potassium chloride in the treatment of the dehydration of diarrhea in infants. J Pediatr 28:541-549

6. Harrison HE 1954 The treatment of diarrhea in infancy. Ped Clin North Am $1: 335-348$

7. Finberg L, Harper PA, Harrison HE, Sack RB 1982 Oral rehydration for diarrhea. J Pediatr 101:497-499 